\title{
Hubungan antara Konsumsi Kopi dengan Gejala Gastroesophageal Reflux Disease (GERD)
}

\author{
Alika Putri Saraswati ${ }^{1}$, Efyluk Garianto ${ }^{2 *}$, Mulyarjo ${ }^{3}$ \\ ${ }^{1,2,3}$ Fakultas Kedokteran Universitas Hang Tuah Surabaya
}

\begin{abstract}
ABSTRAK
Gastroesophageal Reflux Disease (GERD) adalah kondisi yang berkembang ketika ada aliran retrograde dari isi gaster sehingga menyebabkan beberapa gejala atau komplikasi. Salah satu faktor risiko dari GERD adalah kebiasaan konsumsi kopi yang tanpa disadari sudah menjadi tren dalam kehidupan sehari-hari. Tujuan penelitian ini adalah untuk mengetahui hubungan antara konsumsi kopi dengan gejala GERD. Penelitian ini merupakan penelitian observasional analitik yang menggunakan desain penelitian cross sectional dengan jumlah sampel 86 orang. Hasil penelitian menunjukkan responden terbanyak adalah perempuan dengan jumlah 66 orang (73,3\%). Dari 86 responden, yang memiliki kebiasaan konsumsi kopi sejumlah 55 orang (64\%) dan yang tidak memiliki kebiasaan konsumsi kopi sejumlah 31 orang (36\%). Responden yang tidak memiliki kemungkinan menderita penyakit GERD berjumlah 74 orang (86.0\%) dan yang memiliki kemungkinan menderita penyakit GERD berjumlah 12 orang (14.0\%). Analisis data menggunakan uji korelasi Spearman menunjukan tidak ada hubungan yang signifikan $(p=0,428)$ antara frekuensi konsumsi kopi dengan gejala GERD. Dari 55 responden yang mengkonsumsi kopi, 12 responden (21,8\%) mengkonsumsi kopi cair siap minum, 19 responden (34,5\%) mengkonsumsi kopi instan bubuk dan 24 responden (43,6\%) mengkonsumsi kopi giling/tubruk. Analisis data menggunakan uji korelasi Spearman menunjukan tidak ada hubungan yang signifikan $(p=0,193)$ antara jenis kopi yang dikonsumsi dengan gejala GERD. Kesimpulan dari penelitian ini adalah tidak ada hubungan yang signifikan antara konsumsi kopi dengan gejala GERD pada mahasiswa Fakultas Kedokteran Universitas Hang Tuah Surabaya angkatan 2016-2018.
\end{abstract}

Kata kunci: konsumsi kopi; jenis kopi; Gastroesophageal Reflux Disease (GERD)

\begin{abstract}
Introduction: Gastroesophageal Reflux Disease (GERD) is a condition that develops when there is the retrograde flow of gastric contents causing some symptoms or complications. One of the risk factors for GERD is the habit of consuming coffee, which has become a trend in everyday life without realizing it. Purpose: The purpose of this study was to determine the relationship between coffee consumption and symptoms of GERD. Method: This research is an analytic observational study using a cross-sectional study design with a sample size of 86 people. Results: The results showed that most respondents were women with a total of 66 people (73.3\%). Of the 86 respondents, 55 people (64\%) had coffee consumption habits and 31 people (36\%) did not. Respondents who did not have the possibility of suffering from GERD were 74 people (86.0\%) and those who had the possibility of suffering GERD were 12 people (14.0\%). Data analysis using the Spearman correlation test showed no significant relationship $(p=0.428)$ between the frequency of coffee consumption and symptoms of GERD. Of the 55 respondents who consumed coffee, 12 respondents (21.8\%) consumed ready-to-drink liquid coffee, 19 respondents (34.5\%) consumed ground instant coffee, and 24 respondents (43.6\%) consumed ground/brewed coffee. Discussion: Data analysis using the Spearman correlation test showed no significant relationship $(p=0.193)$ between the type of coffee consumed and the symptoms of GERD. The conclusion of this study is that there is no significant relationship between coffee consumption and GERD symptoms in students of the Faculty of Medicine, University of Hang Tuah Surabaya, class 2016-2018.
\end{abstract}

Keywords: coffee consumption; coffee types; Gastroesophageal Reflux Disease (GERD)

*Korespondensi penulis:

Nama : Efyluk Garianto

Instansi : Fakultas Kedokteran Universitas Hang Tuah Surabaya

Alamat : Komplek Barat RSAL Dr. Ramelan, Jl. Gadung No. 1, Surabaya, Jawa Timur, Telp.: +62-31-8433626

Email :dr.efygar@gmail.com 


\section{Pendahuluan}

Kopi adalah salah satu minuman paling populer dan dikonsumsi secara luas di seluruh dunia, termasuk di Indonesia. Tradisi minum kopi bukan hanya untuk sekedar mengatasi rasa haus, tetapi juga berkaitan dengan aktivitas sehari-hari. Sehingga tren konsumsi kopi terus meningkat dan tanpa disadari tradisi minum kopi ini telah menjadi bagian dari gaya hidup. ${ }^{1,2}$

Terdapat beberapa motif utama untuk konsumsi kopi. Namun, motif yang paling berpengaruh dalam konsumsi kopi adalah motif fungsional (functional) dan kepuasan (pleasure). Motif fungsional dari konsumsi kopi antara lain untuk tetap terjaga, meningkatkan kewaspadaan dan meningkatkan energi fisik serta motif kepuasan yaitu meningkatkan suasana hati, kenikmatan dan rileks. ${ }^{3}$ Mahasiswa kedokteran lebih mungkin mengkonsumsi minuman yang mengandung kafein dan terpapar stres tinggi serta jam belajar yang berat. Alasan utama dibalik konsumsi kafein pada mahasiswa, seperti kopi adalah agar lebih terjaga dan agar tetap terbangun serta keadaan yang secara umum mendorong konsumsi kafein adalah selama masa ujian. ${ }^{4}$

Kopi merupakan campuran bahan-bahan kimia yang kompleks dan merupakan sumber utama kafein pada banyak orang, termasuk pada mahasiswa. Kopi juga mengandung beribu-ribu bahan kimia lainnya, termasuk karbohidrat, lipid, senyawa nitrogen, vitamin, mineral, alkaloid dan senyawa fenolik. ${ }^{5,6}$ Kafein yang terkandung di dalam kopi memiliki beberapa efek pada tubuh, baik efek positif maupun negatif. Efek positif antara lain menajamkan logika, konsentrasi, meningkatkan ketenangan serta meningkatkan daya tahan fisik. ${ }^{7}$ Sedangkan efek negatif kafein antara lain menurunkan kualitas tidur, ${ }^{8}$ palpitasi dan peningkatan frekuensi urinasi. ${ }^{9}$

Konsumsi kopi secara reguler juga dapat menyebabkan reflux gastroesophageal dan meningkatkan paparan esofagus bagian bawah terhadap asam lambung. Heartburn merupakan gejala yang paling sering dilaporkan setelah mengkonsumsi kopi. Telah didemonstrasikan bahwa kopi berkontribusi pada refluks gastroesophageal. Kopi menstimulasi sekresi gastrin dan sekresi asam. Kafein juga dapat mempengaruhi fungsi esofageal, menyebabkan penurunan tekanan lower esophageal sphincter (LES) basal dan kontraksi esofagus distal, yang diketahui dapat berkontribusi pada refluks, sehingga isi gaster naik ke esophagus. ${ }^{10}$

GERD adalah sebuah penyakit akibat kerusakan lower esophageal sphincter (LES) yang progresif sehingga menyebabkan kegagalan LES dan reflux. ${ }^{11}$ Prevalensi GERD di seluruh dunia adalah kurang lebih 15\%-25\%, sementara prevalensi di Asia Timur sebelum tahun 2005 adalah 2,5\%-4,8\%, sedangkan pada tahun 20052010 menjadi 5,2\%-8,5\%. ${ }^{12,13}$ Prevalensi GERD pada populasi urban di Indonesia adalah 9,35\%. ${ }^{14}$ Berlandaskan uraian tersebut, maka penelitian ini bertujuan untuk mengetahui hubungan antara konsumsi kopi dengan gejala GERD pada mahasiswa Fakultas Kedokteran Universitas Hang Tuah Surabaya angkatan 2016-2018.

\section{Metode}

Penelitian ini adalah penelitian kuantitatif dengan metode kuesioner dan menggunakan teknik proportionate stratified random sampling. Variabel bebas dalam penelitian ini adalah konsumsi kopi. Konsumsi kopi yang diteliti adalah frekuensi konsumsi kopi dan jenis kopi yang dikonsumsi. Indikator yang digunakan adalah Food Frequency Questionnaire (FFQ). Cara pengukuran frekuensi konsumsi kopi dilakukan dengan mengukur frekuensi kebiasaan konsumsi kopi, terdiri dari tidak mengkonsumsi kopi (0 cangkir per minggu), <1 cangkir per minggu, 1-6 cangkir per minggu, 1 cangkir per hari dan $\geq 2$ cangkir per hari ( 1 cangkir sama dengan $250 \mathrm{ml})$. Sedangkan, untuk jenis kopi, kopi digolongkan menjadi kopi siap minum (seperti kopi kemasan kaleng, botol dan kardus 
karton), kopi instan bubuk (sachet) dan kopi giling/tubruk. Skala pengukuran variabel frekuensi konsumsi kopi adalah skala ordinal, sedangkan variabel jenis kopi yang dikonsumsi adalah skala nominal. Variabel terikat dalam penelitian ini adalah gejala GERD. Gejala GERD adalah gejala yang disebabkan oleh kondisi yang berkembang ketika ada aliran retrograde dari isi gaster. Gejala GERD antara lain adanya heartburn, regurgitasi, nyeri ulu hati, mual, serta kesulitan tidur malam karena heartburn dan/atau regurgitasi. Indikator yang digunakan adalah GERD-Questionnaire (GERD-Q). ${ }^{15}$ Cara pengukuran dilakukan dengan melihat skor GERD-Q, skor $\leq 7$ berarti kemungkinan tidak menderita GERD, sedangkan untuk skor 8-18 berarti kemungkinan menderita GERD. Skala pengukuran variabel ini adalah skala nominal. Analisis data menggunakan uji korelasi Spearman. Penelitian ini dilaksanakan di Fakultas Kedokteran Universitas Hang Tuah Surabaya dan waktu penelitian dilaksanakan pada bulan September sampai Desember 2019.

\section{Hasil dan Pembahasan}

Data yang diperoleh dari penelitian akan dibuat dalam bentuk tabel, narasi dan gambar. Pada hasil pengolahan data yang dibuat akan dibagi menjadi dua bagian, yaitu data umum dan data khusus. Data umum merupakan gambaran umum dari penelitian berupa data yang didapatkan dari responden (kebiasaan konsumsi kopi dan gejala GERD). Data khusus berisikan hasil analisa statistik antar variabel dengan menggunakan uji korelasi Spearman.

Responden yang berpartisipasi sebanyak 86, dengan distribusi responden laki-laki sebanyak 21 orang $(24,4 \%)$ dan responden perempuan sebanyak 65 orang $(75,6 \%)$. Usia responden berkisar antara 17 sampai 23 tahun. Terdapat $1(1,2 \%)$ responden yang berusia 17 tahun, $4(4,7 \%)$ responden berusia 18 tahun, 24 $(27,9 \%)$ responden berusia 19 tahun, $29(33,7 \%)$ berusia 20 tahun, $21(24,4 \%)$ responden berusia 21 tahun, $6(7,0 \%)$ berusia 22 tahun dan $1(1,2 \%)$ responden berusia 23 tahun.

Tabel 1. Distribusi Frekuensi Konsumsi Kopi Responden

\begin{tabular}{lcc}
\hline Kategori & Frekuensi & Persentase (\%) \\
\hline $\begin{array}{l}\text { 0 cangkir } \\
\text { (tidak }\end{array}$ & 31 & 36 \\
konsumsi \\
kopi) \\
$\begin{array}{l}1 \text { cangkir } \\
\text { per minggu }\end{array}$ & 20 & 23,3 \\
$\begin{array}{l}1-6 \text { cangkir } \\
\text { per minggu }\end{array}$ & 21 & 24,4 \\
$\begin{array}{l}1 \text { cangkir } \\
\text { per hari }\end{array}$ & 11 & 12,8 \\
$\geq 2$ cangkir & 3 & 3,5 \\
per hari & & \\
\hline
\end{tabular}

Tabel 2. Distribusi Jenis Kopi Yang Paling Sering Diminum oleh Responden

\begin{tabular}{lcc}
\hline Kategori & Frekuensi & Persentase (\%) \\
\hline $\begin{array}{l}\text { Kopi cair } \\
\text { siap minum }\end{array}$ & 12 & 21,8 \\
$\begin{array}{l}\text { Kopi instan } \\
\text { bubuk }\end{array}$ & 19 & 34,5 \\
$\begin{array}{l}\text { Kopi } \\
\text { giling/tubruk }\end{array}$ & 24 & 43,6 \\
\hline
\end{tabular}

Berdasarkan tabel 1 diketahui bahwa dari 86 responden, responden terbanyak $(36,0 \%)$ adalah yang mengkonsumsi 0 cangkir kopi (tidak mengkonsumsi kopi), dan 3 responden paling sedikit (3,5\%) adalah responden yang mengkonsumsi $\geq 2$ cangkir kopi per hari. Sedangkan pada tabel 2, dapat diketahui bahwa dari 86 responden, terdapat 55 responden yang mengkonsumsi kopi, jenis kopi yang paling sedikit dikonsumsi oleh responden adalah kopi cair siap minum. Selanjutnya untuk jenis kopi paling banyak dikonsumsi oleh responden $(43,6 \%)$ adalah kopi giling/tubruk. 
Tabel 3. Distribusi Skor GERDQ Responden

\begin{tabular}{lcc}
\hline Hasil GERDQ & Frekuensi & Persentase (\%) \\
\hline $\begin{array}{l}\text { Kemungkinan } \\
\text { tidak menderita }\end{array}$ & 74 & 86 \\
$\begin{array}{l}\text { GERD } \\
\begin{array}{l}\text { Kemungkinan } \\
\text { menderita GERD }\end{array}\end{array}$ & 12 & 14 \\
\hline
\end{tabular}

Distribusi skor GERDQ digambarkan pada tabel 3. Berdasarkan tabel 3 di atas, dapat diketahui bahwa dari 86 responden, terdapat 74 responden $(86.0 \%)$ yang kemungkinan tidak menderita GERD dan 12 responden (14.0\%) yang kemungkinan menderita GERD. Maka, kesimpulan dari hasil tersebut adalah jumlah responden yang kemungkinan tidak menderita GERD lebih banyak dibandingkan jumlah responden yang kemungkinan menderita GERD.

Tabel 4. Tabulasi Silang Frekuensi Konsumsi Kopi dengan Skor GERDQ

\begin{tabular}{lcc}
\hline Tabulasi & \multicolumn{2}{c}{ Hasil GERDQ } \\
\cline { 2 - 3 } & $\begin{array}{c}\text { Kemungkinan } \\
\text { tidak } \\
\text { menderita } \\
\text { GERD }\end{array}$ & $\begin{array}{c}\text { Kemungkinan } \\
\text { menderita } \\
\text { GERD }\end{array}$ \\
\cline { 2 - 3 } $\begin{array}{l}\text { Frekuensi } \\
\text { minum } \\
\text { kopi }\end{array}$ & $\mathrm{N}=74$ & $\mathrm{~N}=12$ \\
\hline $\begin{array}{l}\text { 0 cangkir } \\
\text { tidak }\end{array}$ & & \\
$\begin{array}{l}\text { konsumsi } \\
\text { kopi) } \\
<1 \text { cangkir } \\
\text { per minggu }\end{array}$ & 17 & 3 \\
$\begin{array}{l}1-6 \text { cangkir } \\
\text { per minggu }\end{array}$ & 17 & 3 \\
$\begin{array}{l}1 \text { cangkir } \\
\text { per hari } \\
\geq 2 \text { cangkir } \\
\text { per hari }\end{array}$ & 10 & 4 \\
\hline
\end{tabular}

Berdasarkan tabel 4, dari 86 responden, terdapat 31 responden yang mengkonsumsi 0 cangkir kopi (tidak mengkonsumsi kopi), dengan 28 responden yang kemungkinan tidak menderita GERD dan 3 responden yang kemungkinan menderita GERD. Terdapat 20 responden yang mengkonsumsi $<1$ cangkir kopi per minggu, 17 di antaranya kemungkinan tidak menderita GERD dan 3 lainnya kemungkinan menderita GERD. Sedangkan yang mengkonsumsi 1-6 cangkir kopi per minggu berjumlah 21 responden, $17 \mathrm{di}$ antaranya kemungkinan tidak menderita GERD dan 4 di antaranya kemungkinan menderita GERD. Total responden yang mengkonsumsi 1 cangkir kopi per hari adalah 11 responden, dengan jumlah 10 responden yang kemungkinan tidak menderita GERD dan 1 orang yang kemungkinan menderita GERD. Responden yang mengkonsumsi $\geq 2$ cangkir per hari berjumlah 3 orang, 2 di antaranya kemungkinan tidak menderita GERD, sedangkan 1 sisanya kemungkinan menderita GERD.

Tabel 5. Tabulasi Silang Jenis Kopi Yang Paling Sering Diminum dengan Skor GERDQ

\begin{tabular}{|c|c|c|}
\hline \multirow{2}{*}{$\begin{array}{l}\text { Tabulasi } \\
\text { Silang }\end{array}$} & \multicolumn{2}{|c|}{ Hasil GERDQ } \\
\hline & $\begin{array}{c}\text { Kemungkinan } \\
\text { tidak } \\
\text { menderita } \\
\text { GERD } \\
\end{array}$ & $\begin{array}{c}\text { Kemungkinan } \\
\text { menderita } \\
\text { GERD }\end{array}$ \\
\hline $\begin{array}{l}\text { Jenis kopi } \\
\text { yang paling } \\
\text { sering } \\
\text { diminum } \\
\end{array}$ & $\mathrm{N}=46$ & $\mathrm{~N}=9$ \\
\hline $\begin{array}{l}\text { Kopi cair } \\
\text { siap minum }\end{array}$ & 12 & 0 \\
\hline $\begin{array}{l}\text { Kopi instan } \\
\text { bubuk }\end{array}$ & 15 & 4 \\
\hline $\begin{array}{l}\text { Kopi } \\
\text { giling/tubruk }\end{array}$ & 19 & 5 \\
\hline
\end{tabular}

Berdasarkan tabel 5, dapat diketahui bahwa dari 86 responden, terdapat 12 responden yang mengkonsumsi kopi cair siap minum dan dari 12 responden tersebut semuanya kemungkinan tidak menderita GERD. Sedangkan, yang mengkonsumsi kopi instan bubuk sebanyak 19 responden, 15 di antaranya kemungkinan tidak menderita GERD dan 4 lainnya kemungkinan menderita GERD. Serta, yang mengkonsumsi kopi giling/tubruk sejumlah 24 orang, dengan 19 responden yang 
kemungkinan tidak menderita GERD dan 5 responden yang kemungkinan menderita GERD.

Tabel 6. Uji Korelasi Spearman Frekuensi Konsumsi Kopi dengan Skor GERDQ

\begin{tabular}{llcc}
\hline \multicolumn{2}{c}{$\begin{array}{c}\text { Uji Korelasi } \\
\text { Spearman }\end{array}$} & $\begin{array}{c}\text { Hasil } \\
\text { GERDQ }\end{array}$ & $\begin{array}{c}\text { Frekuensi } \\
\text { konsumsi } \\
\text { kopi }\end{array}$ \\
\hline Hasil & $\begin{array}{l}\text { Correlation } \\
\text { Coefficient }\end{array}$ & 1,000 & 0,086 \\
GERDQ & $\begin{array}{l}\text { Sig. (2- } \\
\text { tailed) }\end{array}$ & & 0,428 \\
& $\begin{array}{l}\text { Correlation } \\
\text { Coefficient } \\
\text { Frekuensi } \\
\text { konsumsi } \\
\text { kopi }\end{array}$ &, 086 & 1,000 \\
& $\begin{array}{l}\text { Sig. (2- } \\
\text { tailed) }\end{array}$ &, 428 & \\
\hline
\end{tabular}

Berdasarkan tabel 6 dapat diketahui bahwa nilai signifikansi $(p)=0,428$, berarti $p>\alpha$ (dengan $\alpha=0,05$ ). Sehingga $\mathrm{H} 0$ diterima dan $\mathrm{H} 1$ ditolak. Jadi, tidak ada hubungan antara frekuensi konsumsi kopi dengan gejala GERD pada mahasiswa Fakultas Kedokteran Universitas Hang Tuah Surabaya angkatan 2016-2018.

Tabel 7. Uji Korelasi Spearman Jenis Kopi Yang Dikonsumsi dengan Skor GERDQ

\begin{tabular}{|c|c|c|c|}
\hline \multicolumn{2}{|c|}{$\begin{array}{l}\text { Uji Korelasi } \\
\text { Spearman }\end{array}$} & $\begin{array}{l}\text { Hasil } \\
\text { GERDQ }\end{array}$ & $\begin{array}{l}\text { Jenis kopi } \\
\text { yang } \\
\text { paling } \\
\text { sering } \\
\text { dikonsumsi }\end{array}$ \\
\hline \multirow{2}{*}{$\begin{array}{l}\text { Hasil } \\
\text { GERDQ }\end{array}$} & $\begin{array}{l}\text { Correlation } \\
\text { Coefficient }\end{array}$ & 1,000 & 178, \\
\hline & $\begin{array}{l}\text { Sig. (2- } \\
\text { tailed) }\end{array}$ & & 193, \\
\hline $\begin{array}{l}\text { Jenis } \\
\text { kopi } \\
\text { yang }\end{array}$ & $\begin{array}{l}\text { Correlation } \\
\text { Coefficient }\end{array}$ & ,178 & 1.000 \\
\hline $\begin{array}{l}\text { paling } \\
\text { sering } \\
\text { dikon- } \\
\text { sumsi }\end{array}$ & $\begin{array}{l}\text { Sig. (2- } \\
\text { tailed) }\end{array}$ & ,193 & \\
\hline
\end{tabular}

Berdasarkan tabel 7, diketahui bahwa nilai signifikansi $(p)=0,193$, yang berarti tidak ada hubungan antara jenis kopi yang dikonsumsi dengan gejala GERD pada mahasiswa Fakultas Kedokteran Universitas Hang Tuah Surabaya angkatan 2016-2018.

Beberapa penelitian menyatakan bahwa terdapat hubungan yang signifikan antara konsumsi kopi dengan GERD. Penelitian yang dilakukan oleh Surdea-Blaga et al. menunjukkan bahwa konsumsi kopi secara reguler dapat menginduksi refluks gastroesofagial dan meningkatkan paparan LES terhadap asam. ${ }^{10}$ Namun, ada beberapa penelitian yang menyatakan sebaliknya. Sebuah penelitian metaanalisis yang dilakukan oleh Kim et al. menyatakan tidak ada hubungan yang signifikan antara konsumsi kopi dan GERD. ${ }^{16}$

Kuesioner GERDQ terdiri atas 6 pertanyaan, 4 di antaranya menilai gejala dan keadaan yang merupakan positive predictors dari diagnosis GERD (heartburn, regurgitasi, gangguan tidur dan penggunaan obat yang dijual bebas). Sedangkan 2 pertanyaan lainnya merupakan negative predictors untuk refluks, seperti mual dan nyeri epigastrik. Responden diminta untuk menjawab masing-masing pertanyaan terkait frekuensi gejala selama satu minggu terakhir menggunakan Likert like scale dari 0 sampai 3 untuk positive predictors dan dari 3 sampai 0 untuk negative predictors. Skor maksimumnya adalah 18 .

Adanya gejala dispepsia (mual dan nyeri epigastrik) yang parah merupakan negative predictor dari GERD, yang dapat menjelaskan skor yang rendah pada GERDQ. ${ }^{17}$ Terdapat beberapa kemungkinan yang menyebabkan hubungan antara konsumsi kopi dengan gejala GERD tidak signifikan pada penelitian ini, antara lain:

1. Usia responden

Gejala GERD secara signifikan lebih prevalen pada kelompok usia yang lebih tua (>55 tahun). ${ }^{18}$ Hal ini sesuai dengan studi terdahulu yang menyatakan bahwa peningkatan insiden GERD berbanding lurus dengan peningkatan 
usia, terutama setelah umur 40 tahun. Sedangkan, pada penelitian ini, usia responden berkisar antara 17 sampai 23 tahun. Hal ini diakibatkan oleh proses penuaan pada lansia, yaitu proses degenerasi tubuh manusia yang bersifat irreversible sehingga mengakibatkan penurunan fungsi fisiologis tubuh secara umum, termasuk pada sistem pencernaan. ${ }^{19} \mathrm{Hal}$ ini serupa dengan penelitian yang dilakukan oleh Arivan dan Deepanjali pada mahasiwa sarjana kedokteran dari sebuah Institut di India, dengan jumlah responden 358 orang. Jumlah mahasiswa yang memenuhi kriteria untuk terdiagnosis GERD sebanyak 18 orang $(5,02 \%){ }^{20}$

2. Penyebab lain adanya gejala GERD pada responden

Terdapat penyebab lain dari timbulnya gejala GERD selain konsumsi kopi, antara lain BMI yang tinggi, tahun terakhir menjadi mahasiswa kedokteran (akibat stres ujian), penggunaan NSAID, tidur yang inadekuat, segera tidur setelah makan malam, tidak sarapan pagi secara reguler dan makan dengan cepat. $^{21}$ Beberapa kondisi psikologis, seperti kecemasan, dapat secara langsung mempengaruhi refluks asam lambung dengan menurunkan tekanan lower esophageal sphincter (LES), mengubab motilitas esofageal, atau meningkatkan produksi asam lambung. ${ }^{22}$ Sebanyak 54,7\% dari 137 responden mahasiswa Fakultas Kedokteran Universitas Hang Tuah angkatan 2015-2017 mengalami kecemasan, serta kecemasan yang paling banyak dialami, yaitu sejumlah $19,7 \%$, adalah kecemasan sangat berat/panik. ${ }^{23}$

\section{Kesimpulan}

Berdasarkan penelitian dapat diambil kesimpulan bahwa tidak ada hubungan antara konsumsi kopi dengan gejala GERD pada mahasiswa Fakultas Kedokteran Universitas Hang Tuah Surabaya angkatan 2016-2018, karena terdapat faktor lain yang mempengaruhi timbulnya GERD

\section{Ucapan Terima Kasih}

Penulis mengucapkan terima kasih yang sebesar-besarnya kepada Fakultas Kedokteran Universitas Hang Tuah Surabaya atas dukungan dan bimbingannya selama penulisan artikel ini.

\section{Referensi}

1. Suisa K, Febrilia V, Santoso T. Gaya Hidup Minum Kopi Konsumen di The Coffee Bean \& Tea Leaf Plasa Tunjungan Surabaya. Jurnal Hospitality dan Manajemen Jasa. 2014;2(2):326-343.

2. Nieber K. The Impact of Coffee on Health. Planta Med. 2017;83(16):1256-1263.

3. Samoggia A, Riedel B. Consumers' Perceptions of Coffee Health Benefits and Motives for Coffee Consumption and Purchasing. Nutrients. 2019;11(3):653.

4. Devi SLS, Abilash SC, Basalingappa S. The Rationale of Caffeine Consumption and its Symptoms During Preparatory and NonPreparatory Days: A Study Among Medical Students. Biomed Pharmacol J 2018;11(2):1153-1159.

5. Bae J-H, Park J-H, Im S-S, Song D-K. Coffee and health. Integrative Medicine Research. 2014;3(4):189-191.

6. Mahoney $\mathrm{CR}$, Giles GE, Marriott BP, Judelson DA, Glickman EL, Geiselman PJ, Lieberman HR. Intake of caffeine from all sources and reasons for use by college students. Clin Nutr. 2019;38(2):668-675.

7. Weinberg, BA, Ekawati RS. The Miracle of caffeine: manfaat tak terduga kafein berdasarkan penelitian paling mutakhir. Bandung; Qanita, 2010.

8. Khairani M. Perbandingan Efek Farmakologi Minuman Kopi Hitam dengan Teh Terhadap Tidur dan Diuresis pada Mahasiswa/i Angkatan 2015 Fakultas Kedokteran Universitas Sumatera Utara. Medan: USU; 2018. 
9. Liveina, Artini IGA. Pola Konsumsi Dan Efek Samping Minuman Mengandung Kafein Pada Mahasiswa Program Studi Pendidikan Dokter Fakultas Kedokteran Universitas Udayana. E-Jurnal Medika Udayana. 2014;3(4):414-426.

10. Surdea-Blaga T, Negrutiu DE, Palage M, Dumitrascu DL. Food and Gastroesophageal Reflux Disease. Curr Med Chem. 2019;26(19):3497-3511.

11. Clarrett DM, Hachem C. Gastroesophageal Reflux Disease (GERD). Mo Med. 2018;115(3):214-218.

12. World Gastroenterology Organisation. Heartburn: A Global Perspective. Milwaukee, WI USA: WGO; 2015.

13. Jung HK. Epidemiology of gastroesophageal reflux disease in Asia: a systematic review. J Neurogastroenterol Motil. 2011 Jan;17(1):14-27.

14. Abdullah M, Makmun D, Syam AF, Fauzi A, Renaldi K, Maulahela H, et al. Prevalence, Risk Factors and Socio-epidemiological Study of Gastroesophageal Reflux Disease: An Urban Population Based Study in Indonesia. Asian Journal of Epidemiology. 2016;9:18-23.

15. Antunes C, Aleem A, Curtis SA. Gastroesophageal Reflux Disease. In: StatPearls. Treasure Island (FL): StatPearls Publishing; 2021.

16. Kim J, Oh SW, Myung SK, Kwon H, Lee C, Yun JM, et al. Association between coffee intake and gastroesophageal reflux disease: a meta-analysis. Dis Esophagus. 2014;27(4):311-7

17. Zavala-Gonzales MA, Azamar-Jacome AA, Meixueiro-Daza A, Ramos A, J JR, RoeschDietlen F, Remes-Troche JM. Validation and diagnostic usefulness of gastroesophageal reflux disease questionnaire in a primary care level in Mexico. J Neurogastroenterol Motil. 2014;20(4):475-82.
18. Moshkowitz M, Horowitz N, Halpern Z, Santo E. Gastroesophageal reflux disease symptoms: prevalence, sociodemographics and treatment patterns in the adult Israeli population. World J Gastroenterol. 2011;17(10):1332-5.

19. Gutschow CA, Leers JM, Schröder W, Prenzel KL, Fuchs H, Bollschweiler E, Bludau M, Hölscher AH. Effect of aging on esophageal motility in patients with and without GERD. Ger Med Sci. 2011;9:22.

20. Arivan R, Deepanjali S. Prevalence and risk factors of gastro-esophageal reflux disease among undergraduate medical students from a southern Indian medical school: a crosssectional study. BMC Res Notes. 2018;11:448.

21. Sharma A, Sharma PK, Puri P. Prevalence and the risk factors of gastro-esophageal reflux disease in medical students. Medical Journal Armed Forces India. 2018;74(3):250-254.

22. Choi JM, Yang JI, Kang SJ, Han YM, Lee J, Lee C, et al. Association Between Anxiety and Depression and Gastroesophageal Reflux Disease: Results From a Large Crosssectional Study. J Neurogastroenterol Motil. 2018;24(4):593-602.

23. Arifni QD. Hubungan Antara Tingkat Kecemasan dengan Perilaku Merokok pada Mahasiswa Laki-laki Angkatan 2015-2017 Fakultas Kedokteran Universitas Hang Tuah Surabaya. Surabaya: Universitas Hangtuah Surabaya; 2018. 